\title{
Generation $Z$ and the Online Gaming Community: a Study of Multicultural Education in Disruptive Era
}

\author{
Jeane Marie Tulung ${ }^{1}$, Febri Kurnia Manoppo ${ }^{2}$, Imriani Moroki ${ }^{3}$ \\ Institut Agama Kristen Negeri Manado, Indonesia \\ jeane.tulung@iakn-manado.ac.id ${ }^{1}$, febrimanoppo@iakn-manado.ac.id ${ }^{2}$, \\ imriani.moroki@gmail.com ${ }^{3}$
}

\begin{abstract}
Disruption era is marked by the emergence of various forms of new innovation products which eventually interrupt the long-existed ones. It also happens in the gaming world characterized by the emergence of online gaming products. The presence of online gaming has formed a community of generation $Z$ which consists of various backgrounds of family, religion, ethnicity, and culture. Thus, Generation $\mathrm{Z}$ can gather and socialize in a community and build networks with others. This study was aimed to describe how great the influence of the online gaming community was to the multicultural education of generation $\mathrm{Z}$ and what the related factors are. A mixed method was used in this study. The result showed that there was a significant influence between variables of the online gaming community to the multicultural education of generation $\mathrm{Z}$ which was caused by several factors, namely: the online gaming community influence the emergence of multicultural tolerance attitude of generation $\mathrm{Z}$; online games were capable in providing an imaginative virtual space; online games created a separated social system for the users; online games as new culture; online games became the gate of entrance to understand the multicultural education, the togetherness principle in virtual space, the new learning experience, and the social narrative in multicultural perspective.
\end{abstract}

Keywords: Generation Z, Online Gaming Community, Multicultural Education, Disruptive Era.

\section{Introduction}

Industrial Revolution 4.0 is a new industrial field. Started from the distributions of new technology, digital technology, and the technology which allows the development of fully automated production process. Industrial Revolution 4.0 creates digital products in the world of traditional and modern industries. The development and formation process of Industry 4.0 brings impact on all fields such as the economic and the social fields [1]. The Innovation of industrial revolution 4.0 indeed gave birth to disruptive era where human life is very close to the technology. Judging historically, the technological advance has helped in increasing the productivity and also in encouraging humans to achieve the better results of work. In the first industrialrevolution, manual laborers were replaced by the loom in textiles manufacturing field. During the revolution, women were being heroes for their nimble fingers and for their skills in operating the loom. They earned high salary in factories producing textiles. In the development of industrial revolution, human works are gradually replaced by mechanical machines operated by humans.

In the second half of the first industrial revolution, the steam engine produced the required energy output. It was able to improve the effectiveness of the work results and at once the process of globalization happened [2]. Globalization causes the disruptive era become the era 
where threats and developments occur side by side. The development of digital technology which produces various types of online games becomes an innovation and at the same time a new threat for human life. Digital technology seems greatly influencing generation $\mathrm{Z}$ and slowly being part of their daily lives. Afterwards, communities of online gaming from various cultures are formed.

Generation $\mathrm{Z}$ are those who are determined to be closely connected, live in the technological era of advanced communication, have a life style driven by technology and productive social media usage [3]. The average students of IAKN Manado are in the category of generation $\mathrm{Z}$. The writers perceive the phenomenon of online games which is so familiar among thestudent. In fact, in the observation, the youth played online games not only as individual but also with several people involved likely forming a gaming community in virtual space. They consisted of various backgrounds of tribe, culture, group, and family. It was the reason of the writers to be interested in investigating about how the influence of online gaming community was to the multicultural educationof generation $\mathrm{Z}$ at IAKN Manado. This study aimed to describe how great the influence of online gaming community was to the multicultural education of generation $\mathrm{Z}$ and what factors were related to the relationships.

\section{Research Method}

This study applied exploratory sequential mixed methods design, a combination between quantitative research with qualitative data analysis. Qualitative method was used first and followed by qualitative method. It was aimed to study the correlation between quantitative and qualitative research design. Therefore, the writers correlate the data processing of online gaming community with questionnaires data of the multicultural tolerance attitude. Data collection technique used questionnaire survey in Google forms distributed to students on 6-9 December 2019.

\subsection{Population and Sample}

The population of this study was the semester five students of IAKN Manado from Faculty of Theology and Faculty of Christian Education. The sample of this study was 100 students.

\subsection{Data Analysis Technique}

Data analysis of this study was intended to identify the effect of the online gaming community to the multicultural tolerance attitude of generation $\mathrm{Z}$ at IAKN Manado. The regression analysis was used in analyzing the data.

The steps of data analysis were as follows:

* prerequisite test using normality and linearity tests:

\section{a) Normality Test}

Normality test was carried out to see whether the data from each variable was normally distributed or not. Data was normally distributed if the significance level value was greater than 0.05 ( $\mathrm{sig}>0.05)$. The normality test used the Kolmogorov Smirnov test through SPSS 26. The following criteria were the results of normality test using the Kolmogorov Smirnov test method: 
1) if the significance was $>0.05$, then the data distribution was normal.

2 ) if the significance was $<0.05$, then the data was not normally distributed.

\section{b) Linearity Test}

Linearity test was used to determine whether the data on independent variables have a linear relationship with the data on the dependent variables. Linearity test on this data was done by using a test for linearity test assisted by the IBM SPSS SPSS 26 program. The testing used Linearity Test with the significance level of 0.05 . If the significance value was $<0.05$, the relationship of the two variables was linear. Meanwhile, if the significance value was $>0.05$, the relationship of the two variables was not linear.

\section{c) Hypothesis Testing}

Hypothesis testing proves that there was a significant influence of the online gaming community to multicultural tolerance attitude of generation $\mathrm{Z}$ at IAKN Manado. This hypothesis testing applied simple regression analysis which was used to predict or to test the effect of independent variables to the dependent variables. Regression analysis in this study used the IBM SPSS 26 program by comparing the significance value with the probability of 0.05 . If the significance value was $<0.05$ then the independent variables significantly affected the dependent variables.In contrast, if the significance value was $>0.05$ then the independent variables did not have any significant effect on the dependent variables.

\section{Result and Discussion}

\subsection{Online Gaming Community and Multicultural Tolerance Attitude}

This study aimed to examine the effect of online gaming community to the multicultural tolerance attitude of the semesterfive students of IAKN Manado. This study used the mixed methods sequential exploratory design. Itwas a combination of quantitative and qualitative research and the data were analyzed by using the quantitative research design first and continued with the qualitative research. For the quantitative research, the correlation research design was used. Nevertheless, in this study the writers correlated the data of the questionnaires results of the online gaming community with the tolerance multicultural attitude. Mechanical analysis of the data in this study used analysis regression linear, an analysis aimed to analyze the relationship between dependent and independent variables. Before the analysis of regression was conducted, validity and reliability tests of the questionnaire were carried out to sort out the invalid and unreliable questions. Afterwards, the prerequisite test analysis was performed using the normality and linearity tests. The result of normality test described that the significance value of the multicultural tolerance attitude questionnaires and the online gaming community questionnaires respectively are 0.070 and $0.071>0.05$.Therefore, it can be said that both questionnaire results was normally distributed. Furthermore, the result of linearity test showed that its significance coefficient value was at 0.018 . Referring to the criteria of the homogeneity test result, the significance value was 0.018 $<0.05$. It can be said that the relationship of both variables was linear. The next step was conducting the research hypothesis testing using linear regression analysis. 
Given the constant value was (a) $=67,976$ and the online gaming community value was (b) $=-0,297$. Based on the linear regression equation $\mathrm{Y}=\mathrm{a}+\mathrm{bX}$, the linear regression equation obtained for this study was

$\mathrm{Y}=67,976-0,297 \mathrm{X}$,

The result of the regression analysis showed that the regression significance value was 0,018 . Referring to the result criteria of the hypothesis testing using linear regression analysis, the significance value was $0.018<0.05$. Therefore, Ha was accepted and Ho was rejected. Because Ha was accepted and Ho was rejected, the hypothesis of the research has been already verified that "There is an influence of online gaming community to the multicultural tolerance attitude of the SemesterFive Students of IAKN Manado".

According to the description above, this study evidenced that the online gaming community significantly affected the emergence of the multicultural tolerance attitude on generation $\mathrm{Z}$ at IAKN Manado. The online gaming community, known as the gamers, effected the development of multicultural tolerance attitude connected among the individuals in the community.

\subsection{Virtual Space}

Online games created a new culture which is also participated in establishing the social and communication norms of the mechanisms involved. It was included the issues of how to understand the social aspects developments of the game, what factors caused the individuals involved in this virtual community and also what evidences show the benefits in the context of other social computation. For instance, it would be useful to understand how the particular social norms were established, and what kind of interactions were performed by the humans involved, as well as how the particular communication mechanism was able to be driven as the new online communication mechanism. Online community was developed to support activities related toemployment, distance education, and other various applications. Klastrup argued that multi- player online games must be considered a multi-world dimension which needs more than a single analytical approach. We could successfully analyze "the old world" like EverQuest as an example of a game and learn a lot about the world functions by watching. For example, in the game mechanism, a person may also see the gameworld like EverQuestpri-marily as social culture by viewing on how the people in EverQuest interact socially with each other [4].

Klastrup found three difference solutions in understanding the game world which needed to collaborate to be complemented [5] :

a) Fiction: a form of trust in which the users are willing to suspend their distrust in the reality of the gameworld.

b) Narrative: a meaningful presentation of a series of events in a symbolic reference frame.

c) Interpretation: in representation form; "what the world like or what it is supposed to be".

Klastrup concluded that interpretational dimension of a virtual world like game is a broad matter to be explored. He suggested that, at least, each of them is needed to be in line with the expectation of humans to be real. Nevertheless, many games, even all games also serve as an interpretation of a particular "real world" in which we live [6].

The writers observed that all fiction, narrative and interpretation became an integrated series in the virtual gaming space. Each online gaming player was able to provide an imaginative virtual space contained particular expectations of the real world. 


\subsection{Social System}

Disruptive era which brings a lot of competition in the digital world also affected the online games. The game development from traditional model showed a process of disruption. In online games, there were also various types of game, for example, the multiplayer game excerpted from Star Wars movie. The game portrayed the fiction planets, such as Tatoonine and Naboo, where the players created a social system which allows them to experience life. Particularly, the Star Wars Galaxy was purposely arranged right after the original action movie in 1977. The multiplayer Game was made based on a well-known story of how to face a very difficult problem [7]. The habit formation of the players scientific thoughts resulted in a cognition experience distributed generally and comprehensively in the game, where the individuals network was made to find out and to make decision which is impossible to be decided by themselves, namely by using a complex communication system and a collaboration learning among the players to achieve practical purpose. The players had skills of using special language forms and narrative skill. Their computer literacy increased. It allowed them to learn the general mechanisms which could lead to success inreal world context, corresponding to what Steinkuehler called an impact in online gaming and the system inside where people mutually teach by sharing information. The increase of users understanding to each other about cultural diversity whether the game created based on the specific cultural system or the other players were from various cultures in the real world. By interacting in this multiplayer online game, they unite people across cultures [8].

According to it, the writers summarized that online gaming in disruptive era created a separated social system for the users. Students who are very familiar with online gaming seem to be bound in a social system as the online gaming citizens connected to each other.

\subsection{Online Gaming Culture}

The game was knotted wider to the social phenomenon in human life and society. In digital age, online gaming emerged as popular recreation activity not only for the young generation, but also for the elderly in various countries. For example, Microsoft has reported that game is on the three-top in Microsoft platform. It showed how great the interest of digital society is to connect to each other through a virtual space in the game. Social media was defined as a group of application -based on internet which built the foundations of ideological and the Web 2.0 technology and allowed the manufacture and the exchange of user creation content. Twothirds of the online adult (65\%) used social media platforms such as Facebook, Twitter, Instagram, Pinterest and they considered socializing with friends, family, colleagues, and acquaintances in their offline life. It becomes the main motivation of people to adopt the using of social media. Nowadays, the use of media and social network has been so engaging in the life of most teenagers [9]. This, online gaming becomes a form of a new social media. It was because the online gaming allows combination of appealing entertainment and multiplayer interactions.

Based on the survey results on 100 respondents, the students of IAKN Manado considered as the generation $\mathrm{Z}$ indicating that the majority of the respondents made online games as new cultures in their world [10], a culture which wasproviding not only emotional entertainment but also a new interaction space with their colleagues. 


\subsection{Gate to the Multicultural Community}

There are millions of people joined the online gaming community every day. Online gaming then attracted the members of the community. They were also intentionally involved in social interaction. Following the game rules wasan unwritten rule required to do. It was the initial entry of this community and the beginning of the social interactions. Online games acted as the early gate or the entrance where the multicultural-social interaction happened. Millions of people mentioned above were consisted of various backgrounds of religion, ethnicity, culture, and education. Most of those who were involved joined playing in a team without looking at religion, tribe, culture, and education. The reason of joining was their interest to the game. The character and atmosphere of the game were also the reasons why they could accept and joined with others from various parts of the world. It was also said by the students who had been interviewed. "We do not focus on the religion matter, but we immediately play the game, we greet each other, we help each other, together we draw up a strategy for victory. Those are the fun things we do in the community"[11].

Based on the analysis of the survey results through google form instrument, it showed that most of generation $\mathrm{Z}$ who played online gaming learned many things about multicultural education. The communities formed not only from the same religion background but also from different religion. They were not merely just from the same tribes and cultures but from various background of tribes and cultures. This multicultural relationships indicated that theonline games became the entrance gate for generation $\mathrm{Z}$ to understand multicultural education.

\subsection{Principles of Togetherness}

No culture they understood in online games other than the culture of the game. It means that they did not emphasize on any culture. Joining with the community means willing to adjust to the culture designed in the game. Generation $\mathrm{Z}$ who used online games really understand the togetherness principles [12]. Togetherness became a binding culture for them. playing online games sometimes made most gamers forget the time and their psychological pressure. Analyzing the psychological pressures could be covered in other study. Perhaps the writers in this study emphasized on the togetherness or solidarity aspect emerged from the online game. Indeed, it is admitted that some negative impacts such as online gaming addiction was needed to be considered by generation $\mathrm{Z}$ and the parents. But one of the positive aspects in online gaming lies on the togetherness principle occurred simultaneously in virtual space.

\subsection{Playing Experience}

When playing online games, they even mapped the strategies and ways to win the game. All players were involved to think of the best thing to do. Their mind was focused on facilitating the colleagues dominated by generation Z. All things in the game was considered as a fun experience. They were brave, simple and practical. The more interesting was the game, the more experience were gained [13]. Some of interesting findings in the online gaming survey were the gamers totality in completing a mission. They would be trained to organize and sharpen a strategy in achieving victory. Possibly it was closely related to the aspects of cognitive development. Online gaming seemingly presented a new learning experience to each individual involved. Art and technology were joint from model and theory 
which was the relationship between what was in the computer and what was in the human mind [14]. Generation Z, which is very familiar with digital technology, was able to integrate the art and technology elements which produced a new model for the users. The students who played online games looked as if they were able to enjoy the playing experience of multidimensional games.

\subsection{Social Narrative}

The data of the survey showed that cross religion conversation could be something fun when merged in online gaming community. People wouldl know each other without feeling unwelcome in the community. Online gaming community was also influenced in terms of making decision [15]. Based on the findings above, the writers concluded that online games could be a social narrative which would help us to connect with various circles without prioritizing the sentiments of ethnic, religion, race and intergroup. Educational value in online gaming community was able to be a multicultural narrative which could be continuously studied and implemented for related parties. Taking into consideration, the multicultural narratives values could be developed to the extent that they did not interfere with the education process for the generation $\mathrm{z}$.

\section{Conclusions}

Online games affected the multicultural education of generation $Z$. There was a space without walls when socializing or involving in the community. The significant influence of the online gaming community variable to the multicultural education was caused by several factors, namely:

a) Online gaming community influenced the emergence of multicultural tolerance attitude on generation $\mathrm{Z}$ at IAKN Manado.

b) Online games were able to provide imaginative virtual space which contains particular expectations of the real world.

c) Online games in disruptive era created a separated social system for the users.

d) Generation $Z$ at IAKN Manado considered online games as new cultures in their world.

e) Online games became the entrance gate for generation $Z$ to understand multicultural education.

f) One of the positive aspects in online games laid on the togetherness principle occurred simultaneously in virtual space.

g) Online games presented a new experience of learning in every individual involved.

h) Online games became a social narrative which would help us to connect with various circles without prioritizing thesentiments of ethnic, religion, race and intergroup. The social narrative was about how to communicate differences in togetherness.

\section{References}

[1] Elena G. Popkova - Yulia V. RagulinaAleksei V. Bogoviz, Industrial Revolution of the 21st Century Study in Systems, Decisions and Control Volume 169, Pg. 3 
[2] Tai Wei Lim, Industrial Revolution 4.0, Tech Giants, and Digital Society, ISBN 978-981-137470-8, 2019, Pg. 4

[3] Shilpa Gaidhani, Lokesh Arora, Bhuvanesh Kumar Sharma, January 2019, UNDERSTANDING Z GENERATION ATTITUDE TO WORKPLACE, Jan 2019

[4] William Sims Bainbridge, Online Multiplayer Games, 2010, ISBN: 9781608451425, ISBN: 9781608451432 DOI 10.2200 / S00232ED1V01Y200912ICR013, Pg. 17

[5] William Sims Bainbridge, Online Multiplayer Games, 2010, ISBN: 9781608451425, ISBN: 9781608451432 DOI 10.2200 / S00232ED1V01Y200912ICR013, Pg. 29

[6] William Sims Bainbridge, Online Multiplayer Games, 2010, ISBN: 9781608451425, ISBN: 9781608451432 DOI 10.2200 / S00232ED1V01Y200912ICR013 Pg. 39

[7] William Sims Bainbridge, Online Multiplayer Games, 2010, ISBN: 9781608451425, ISBN: 9781608451432 DOI 10.2200 / S00232ED1V01Y200912ICR013 Pg. 56

[8] William Sims Bainbridge, Online Multiplayer Games, 2010, ISBN: 9781608451425, ISBN: 9781608451432 DOI 10.2200 / S00232ED1 V01Y200912ICR013 Pg. 93

[9] Guo Freeman, Online Multiplayer Games Origins, Players, and Social Dynamics, 2018 by Taylor \& Francis Group, 978-1-4987-6765-1 (Paperback) 978-0-8153-9287-3 (Hardback), Pg.17

[10] Google form survey on December 6-9, 2019

[11] Google form survey on December 6-9, 2019

[12] Google form survey on December 6-9, 2019

[13] Google form survey on December 6-9, 2019

[14] Guo Freeman, Online Multiplayer Games Origins, Players, and Social Dynamics, 2018 by Taylor \& Francis Group, 978-1-4987-6765-1 (Paperback) 978-0-8153-9287-3 (Hardback), Pg .17

[15] Google form survey on December 6-9, 2019 